\title{
Tomato pomace protects against mercuric chloride-induced neuro- degeneration and motor abnormality in adult rat
}

\author{
O. OWOEYE ${ }^{1^{*}}$ and E.O FAROMBI ${ }^{2}$ \\ ${ }^{1}$ Department of Anatomy, College of Medicine, University of Ibadan, Ibadan, Nigeria. \\ ${ }^{2}$ Drug Metabolism \& Toxicology Research Laboratories, Department of Biochemistry, \\ College of Medicine, University of Ibadan, Nigeria. \\ *Corresponding author, E-mail: o.owoeye@mail.ui.edu.ng; oowoeye2001@yahoo.com; \\ Tel: +234-8033239973; Fax: 234-2-8103043
}

\begin{abstract}
Mercuric chloride is an environmental toxicant that causes health hazards. One of the mechanisms of its toxicity is oxidative stress which antioxidants are expected to ameliorate. Tomato is reported to possess antioxidant activity and this study investigated tomato pomace powder's (TPP) effect on mercuric chloride $\left(\mathrm{HgCl}_{2}\right)$ intoxication in rats. Thirty male rats were assigned randomly into five groups $(\mathrm{n}=6)$ : Control; Propylene glycol; TPP (50 mg/kg bwt) for 19 days; $\mathrm{HgCl}_{2}(4 \mathrm{mg} / \mathrm{bwt})$ from day 5 to 19 of the experiment; TPP $+\mathrm{HgCl}_{2}$, TPP $(50 \mathrm{mg} / \mathrm{kg}$ bwt $)$ for 19 days $+\mathrm{HgCl}_{2}(4 \mathrm{mg} / \mathrm{bwt})$ from day 5 to 19 of the experiment. All treatments were given orally by gavage. Behavioural tests were conducted on the $20^{\text {th }}$ day and rats were euthanized the same day. Blood parameters and brain tissue were examined with regard to micro-anatomical parameters. Mercuric chloride significantly reduced neutrophils, thrombocytes, transitions, rearings, forelimb grip strength and latency of geotaxis. Histologically, $\mathrm{HgCl}_{2}$ induced alterations in the cerebral cortex, dentate gyrus, cornu ammonis 3 , and cerebellum of rats. Treatment with TPP before $\mathrm{HgCl}_{2}$ administration significantly reduced the effect of $\mathrm{HgCl}_{2}$ on these parameters. These observations may be partly attributed to the antioxidant property of TPP. TPP demonstrated protective effects against $\mathrm{HgCl}_{2}$-induced alteration of motor anomaly and microanatomy of rats' cerebral cortex, hippocampus and cerebellum. TPP may be a valuable agent in prevention of acute neuropathy caused by inorganic mercury intoxication.

(C) 2015 International Formulae Group. All rights reserved.
\end{abstract}

Keywords: Mercuric chloride, cortical neurons, granule cells, cornu ammonis3 pyramidal neurons, Purkinje neurons, tomato.

\section{INTRODUCTION}

Despite being recognized as a hazardous environmental toxicant and industrial pollutant, which on exposure causes a wide range of adverse health problems (Xu et al., 2012), inorganic mercury is widely used in certain batteries and is an essential component of fluorescent light bulbs (Augusti et al., 2007). Other applications of mercury include industrial, where it has been found useful as components of thermometers, thermostats, and in gold mining (Augusti et al., 2007; Clarkson et al., 2003). Medically, it has found use as components of sphygmomanometers, clinical thermometers, disinfectant and vaccines in which the 
antimicrobial preservative, thimerosal, contains $49.9 \%$ mercury by weight (Guzzi et al., 2012). Therapeutically, mercury is used as a cathartic, anti-inflammatory, diuretic, and in dental amalgams.

Mercury is released in the environment by human activity such as mining, extensive industrial and agricultural usage, and other industrial release. Human exposure to mercury could be via its vapour, mercury chloride, or methyl mercury compounds (Rao and Purohit, 2011). Inorganic mercury, present in water sediments, is subject to bacterial conversion to methylmercury compounds that are bio-accumulated in the aquatic food chain to reach the highest concentration in predatory fish. The general populations are thus exposed to methyl mercury through the diet, the main source being fish consumption (Coccine et al., 2000; Uma et al., 2012). Mercury exhibits toxicity in form of neurotoxicity, nephrotoxicity, reproductive toxicity and gastrointestinal toxicity with ulceration and haemorrhage (Rao and Purohit, 2011; Uma et al., 2012; Xu et al., 2012).

Mechanisms proposed for inorganic mercury toxicity include the binding of mercuric ions to sulfhydryl groups resulting in decreased glutathione levels and depletion of thiols leading to an increase of reactive oxygen species (ROS), ultimately leading to oxidative stress and increased neurotoxicity (Stohs and Bagchi, 1995; Hussain et al., 1997; Rao and Purohit, 2011). Antioxidants are known to ameliorate oxidative stress by inhibiting or scavenging the free radicals generated to prevent damage and augmentation with diet-derived antioxidants like ascorbic acid, vitamin E, carotenoids and polyphenols, may mitigate or prevent oxidative tissue damage (Farombi and Owoeye, 2011). Also, the use of naturally occurring antioxidant that are plant-based, are being encouraged due to reports showing the reduction of toxicity of mercuric chloride by natural plant based substances like Curcumin (Rao and Patel, 2013), Zingiber officinale
(Ezeuko et al., 2007) and Tabernaemontana coronaria (Uma et al., 2012).

Tomato or Lycopersicon esculentum Mill belongs to the family of Solanaceae, and phytochemical investigations have shown that one of its constituent's lycopene is a potent carotenoid antioxidant (Augusti et al., 2007; Wattanathorn et al., 2012). Tomatoes are widely consumed either raw or after processing and can provide a significant proportion of the total antioxidants in the diet. It is an excellent source of many nutrients and secondary metabolites that are important for human health; minerals, vitamin $\mathrm{C}$ and $\mathrm{E}$, carotene, lycopene, flavonoids, and phenolics (Khalaf et al., 2014). Tomato pomace powder (TPP) made from tomato has been beneficial in protecting against experimental stroke (Hsiao et al., 2007; Wattanathorn et al., 2012).

Mercury is a major neurotoxicant, primarily affecting brain tissue causing brain damage ultimately affecting the function of brain parts such as the cerebral cortical neurons, cerebellum and the visual cortex, and might also cause behavioural and cognitive changes (NRC, 2000; Xu et al., 2012). A report by Xu et al. (2012) indicated that the areas of the brain most often affected by mercury intoxication are the cerebral cortex and the cerebellum. Functionally, the cerebral hemisphere and the cerebellum are responsible for regulating primary sensory functions and motor coordination, balance and postural stability respectively. It is worthwhile however, to study, in addition the hippocampus which is associated with memory and learning since injury to any of these brain parts may lead to neurological deficits (Snell, 2006; Scharfmann, 2012).

Literature is scanty concerning the effect of tomato on mercuric chloride-induced alteration of the microanatomy of rats' brain hence this study to investigate a possible protective role utilizing its known antioxidant property. This study aimed at answering the question: "Can Lycopersicon esculentum as TPP treatment have any protective role on mercury chloride-induced alteration of the microanatomy of rat brain?" 


\section{MATERIALS AND METHODS \\ Experimental animals}

Thirty male albino rats acquired from the Central Animal House of College of Medicine, University of Ibadan, Nigeria, were used for this study. They were housed in transparent plastic cages with wood shavings at a freely ventilated and naturally illuminated Animal House of Department of Veterinary Physiology, Biochemistry and Pharmacology, University of Ibadan. Rats were fed with standard rat diet produced by Vital Feeds, Jos, Nigeria, and water provided ad libitum. The experimental protocols were carried out according to the approval and guidelines given by the University of Ibadan Ethical Committee, which also conformed to the acceptable guidelines on the ethical use of animals in research (Public Health Service, 1996).

\section{Tomato Pomace Powder (TPP) Preparation and Administration}

Fresh tomato fruits (Lycopersicon esculentum) were purchased from Bodija market, Ibadan, Nigeria. TPP was prepared according to the published method of Wattanathorn et al. (2012). Briefly, the fresh tomatoes were washed and cut into small pieces after which the tomato juice was extracted to retain the skin, pulp and seeds which were then dried in an oven at $50{ }^{\circ} \mathrm{C}$ for 2 hours. The dried parts were weighed and grinded in a blender and the resulting powder termed Tomato Pomace Powder (TPP) was kept in a clean airtight plastic container at room temperature till ready for use. The administration of TPP was performed by using propylene glycol as vehicle.

\section{Chemicals}

Mercuric chloride (LobaCheme PVT Ltd, Mumbai, 40005, India) was purchased from Julimark Enterprises, Yemetu, Adeoyo Road, Ibadan, Nigeria. Ketamine was manufactured by Rotex Medica, Trittau, Germany. Propylene glycol (PG) was manufactured by Guangdong Guanghua Science Tech. Co Ltd. (China). All other reagents were of analytical grade and were obtained from the British Drug Houses (Poole, Dorset, UK).

\section{Preparation and administration of PG}

Propylene glycol was the vehicle for TPP and was administered orally at a dose of $0.2 \mathrm{~mL} / \mathrm{rat} /$ daily using gavage.

\section{Preparation of $\mathrm{HgCl}_{2}$ solution}

The measured dose of mercuric chloride $\left(\mathrm{HgCl}_{2}\right)$ was dissolved in distilled water for oral administration.

\section{Experimental design}

After the period of acclimatization, the thirty male Wistar rats weighing $86 \mathrm{~g}-131 \mathrm{~g}$ were assigned into five treatment groups $(n=6)$. Male rats were used to avoid confounders such as sex hormone, lactation, and pregnancy, which are inherent to females and also the different metabolic rate peculiar to the genders (male and female). All treatments were given through oral gavage. The dose of $\mathrm{HgCl}_{2}$ was based on the method of Sheikh et al. (2013) while that of TPP was based on the method of Wattanathorn et al. (2012). Animal grouping and treatment is detailed in Table 1.

\section{Behavioural tests}

Rats were weighed and then subjected to behavioural tests on the $20^{\text {th }}$ day of the experiment. We investigated the effects of exposure to $\mathrm{HgCl}_{2}$ on the rat nervous system, by performing the following behavioural tests: (1) open field test, (2) forelimb grip strength test, (3) negative geotaxis. These tests were performed to screen the muscle coordination activity and explorative behaviours of rats.

\section{Open field test}

This test which assesses the general locomotive activity of rodents was performed according to the method described by Olopade et al. (2012). Briefly, each rat was placed in an open field, a 72 by $72 \mathrm{~cm}$ square box with lines on the floor dividing it into 18 by $18 \mathrm{~cm}$ square that allowed the definition of central 
and peripheral parts. At the beginning of the session, each rat was placed in the centre of the arena and its activity was recorded for a duration of 5 minutes during which the following parameters were assessed: (a) horizontal movements, measured by the number of transitions/lines crossed, (b) vertical movement or rearing (the number of times the rat balances on its hind feet), (c) centre time (length of time spent in the centre square) and (d) number of faecal boluses passed. All these parameters were assessed and manually recorded by the same set of observers. The rearing numbers indicated vertical and exploratory activities. At the end of each session, each rat was removed from the open field and the experimental chamber was thoroughly cleaned with a damp cloth and dried.

\section{Forelimb grip strength test}

This is a test of muscular strength in the forelimbs (Tamashiro et al., 2000). In this test, the forepaws were placed on a horizontally suspended metal wire $2 \mathrm{~mm}$ in diameter, $1 \mathrm{~m}$ in length and placed $1 \mathrm{~m}$ above a landing area filled with soft bedding. The length of time each rat was able to stay suspended before falling off the wire was recorded; a maximum of 2 minutes was given to each rat. Each animal was given two trials with a $30 \mathrm{~min}$ inter-trial rest interval. This test assessed muscle strength and balance.

\section{Negative geotaxis}

Negative geotaxis was tested by placing rats head-down on an inclined plane and then watched the rat orient in a head-up direction (Kreider and Blumberg, 1999). The time it takes for the rat to orient in a head-up direction was recorded with a stopwatch. The average of two trials was obtained.

\section{Sample collection and histological preparation}

On day $20^{\text {th }}$ of the experiment, having completed the behavioural tests, all animals in all groups were weighed, anaesthetised with ketamine $(100 \mathrm{mg} / \mathrm{kg})$ intraperitoneally. Blood was collected by retro-orbital venous plexus puncture into heparinized bottles for haematological parameters. Following cervical dislocation, each rat was decapitated at the cervico-medullary junction for uniformity and the skulls opened after which the brains were quickly extracted. The cerebellum and brain of each rat were dissected and then preserved in $10 \%$ neutral buffered formalin and later processed for histology by paraffin embedment technique.

\section{Histology}

With careful dissection, the cerebellum from each group was obtained and homologous sampling was assured by obtaining transverse sections of the right cerebellum from each specimen from the lateral zone portions of the cerebella hemisphere for uniformity. Coronal sections of the right half of each brain were made to obtain samples of the cerebral cortex and hippocampal tissue. The tissues were sectioned at 5-6 $\mu \mathrm{m}$ thickness and then stained with haematoxylin and eosin according to the method of Bancroft and Gamble (2008) to assess neuronal damage in the cerebral cortex, cerebellum and hippocampus. Slides were viewed with an Olympus $\mathrm{CH}$ (Japan) light microscope with $16 x$ objective. The image capturing was performed with a Sony DSC-W 3 digital camera (Japan) and photomicrograph calibration was done with Image $\mathbf{J}$ (Abramoff et al., 2004).

\section{Determination of haematological values}

K2 EDTA-added whole blood samples were used for haematological analyses immediately after collection with the aid of Sysmex Automated Haematology (KX-21, Kobe, Japan) Analyzer. The haematocrit or packed cell volume (PCV), haemoglobin $(\mathrm{Hb})$, red blood cell count (RBC), mean cell volume (MCV), mean cell haemoglobin $(\mathrm{MCH})$, mean cell haemoglobin concentration (MCHC) and white blood cell count (WBC) were obtained. 


\section{Statistical analysis}

All data were expressed as means \pm standard deviation. Data were analysed using one-way analysis of variance (ANOVA) using GraphPad Prism TM 4.0 version software, San Diego, CA, USA. Post hoc comparisons were performed after ANOVA using Dunnett's test. Statistical significance was set at $\mathrm{p}<0.05$.

\section{RESULTS}

\section{Haematological parameters}

Table 2 presents a summary of the effect of TPP and $\mathrm{HgCl}_{2}$ on erythrocyte indices of the rats. There were no significant alteration by $\mathrm{HgCl}_{2}$ of the packed cell volume (PCV), haemoglobin level $(\mathrm{HgB})$, red blood cell count (RBC), mean corpuscular volume (MCV), and mean corpuscular haemoglobin concentration (MCHC).Table 3 shows that $\mathrm{HgCl}_{2}$ caused a $21 \%, 32 \%, 50 \%$, and $20 \%$ reduction of total white blood cell (WBC), lymphocytes, neutrophils, and thrombocytes respectively, which was significant at significant at $\mathrm{p}<0.05$ when compared with control. However, pre-treatment of $\mathrm{HgCl}_{2}$ with TPP ameliorated these effects by $65 \%$, and $16 \%$ increases in neutrophils, and thrombocytes respectively, significant at $\mathrm{p}<0.05$ when compared with the $\mathrm{HgCl}_{2}$ group, whereas the $12 \%$ and $33 \%$ increases in WBC and lymphocytes respectfully were not significant.

\section{Behavioural parameters}

The data presented in Figure 1A and 1B show that $\mathrm{HgCl}_{2}$-treated rats were less active in horizontal, exploratory, and vertical movements (rearings) compared to controls which was significant $(p<0.05)$. The forelimb grip strength test (Figure 1C) which is a measure of the muscular strength in the forelimbs showed a reduction of muscular strength, with a significantly shorter drop-off time in the $\mathrm{HgCl}_{2}$-treated group $(\mathrm{p}<0.05)$. Similarly, $\mathrm{HgCl}_{2}$ treatment caused a significant reduction in the negative geotaxis when compared with the control (Figure 1D). However, pre-treatment with TPP ameliorated forelimb strength and movements significantly $(\mathrm{p}<0.05)$, whereas increase in geotaxis was not significant.

\section{Histological parameters \\ Cerebral cortex}

Mercuric chloride treatment caused degeneration of some cortical neurons shown by scattered pyknotic neurons (Figure 2D) when compared with control (Figure 2A) and other treatment groups (Figures 2B and 2C). Pre-treatment with TPP caused a reduction of the effect of $\mathrm{HgCl}_{2}$ treatment as shown in Figure 2E, where the cortical neurons showed normal round or ovoid nuclei exhibiting dispersed chromatin.

\section{Dentate gyrus}

In Figures 3A, 3B, and 3C the microscopic features of dentate gyrus showing molecular layer, granule cell layer and polymorphic layer are presented. The effect of $\mathrm{HgCl}_{2}$ is shown in Figure 3D with some of the granule cell neurons undergoing degeneration (arrowheads) in the inner subgranular zone whereas the outer granule cell neurons show normal histological features (arrows). Figure $3 \mathrm{E}$ shows some ameliorative effect of pretreatment with TPP before $\mathrm{HgCl}_{2}$ administration when compared with Figure $3 \mathrm{D}$.

\section{Cornu ammonis3 (CA3)}

The normal histological features of the stratum oriens, stratum pyramidalis, and stratum radiatum typical of CA3 subfield of the hippocampal formation are shown in Figures 4A, 4B, and 4C. In Figure 4D, $\mathrm{HgCl}_{2}$ toxicity on the pyramidal neurons was exhibited by dark staining neurons that are degenerating (pyknotic neurons, blue arrowheads; neurons exhibiting karyolysis, black arrowheads). Figure 4E shows the effect of pre-treatment with TPP before $\mathrm{HgCl}_{2}$, the pyramidal neurons show normal features when compared with the $\mathrm{HgCl}_{2}$ group of Figure 4D. 


\section{Cerebellum}

In Figures 5A, 5B and 5C, the normal histological layers of an adult rat cerebellum namely: granular, molecular, and Purkinje are shown. The Purkinje cells of the $\mathrm{HgCl}_{2}$ rats are noted to be eosinophilic, the majority lacking basophilic staining (Figure 5D) when compared with the control and the other groups. In comparison to the effects observed in Figure 5D, the basophilic staining of the Purkinje cells are noted in Figure 5E when compared with the $\mathrm{HgCl}_{2}$ treated group.

Table I: Animal grouping and treatment.

\begin{tabular}{ll}
\hline Grouping & Treatment \\
\hline GroupI & Control, received rat chow and water daily. \\
Group II & PG, Propylene glycol, $0.2 \mathrm{~mL} / \mathrm{rat} /$ day daily for 19 days. \\
Group III & $\mathrm{TPP}$ dose of $50 \mathrm{mg} / \mathrm{kg}$ bwt for 19 days. \\
Group IV & $\mathrm{HgCl}_{2}(4 \mathrm{mg} / \mathrm{bwt})$ daily for 5 days from day 15 of the experiment. \\
Group V & $\mathrm{TPP}+\mathrm{HgCl}_{2}, \mathrm{TPP} 50 \mathrm{mg} / \mathrm{kg}$ for 19 days $+\mathrm{HgCl}_{2}(4 \mathrm{mg} / \mathrm{bwt})$ daily for 5 days from \\
& day 15 of the experiment.
\end{tabular}

TPP, tomato pomace powder; $\mathrm{HgCl}_{2}$, mercuric chloride.

Table 2: Effect of TPPandHgCl $\mathrm{Hg}_{2}$ on Erythrocyte indices of male Wistar rats.

\begin{tabular}{|c|c|c|c|c|c|}
\hline Groups & PCV (\%) & HgB (g/dL & RBC $\left(\times 10^{6} / \mu L\right)$ & MCV (fL) & $\operatorname{MCHC~(g/dL)~}$ \\
\hline Control & $45.6 \pm 3.4$ & $15.3 \pm 0.6$ & $7.3 \pm 0.06$ & $61.0 \pm 1.3$ & $33.2 \pm 0.6$ \\
\hline PG Alone & $44.5 \pm 3.3$ & $14.6 \pm 0.9$ & $7.1 \pm 0.53$ & $59.0 \pm 1.7$ & $33.0 \pm 0.6$ \\
\hline TPP & $42.0 \pm 2.0$ & $14.5 \pm 0.6$ & $7.4 \pm 1.03$ & $59.0 \pm 1.8$ & $33 \pm 0.0$ \\
\hline $\mathrm{HgCl}_{2}$ & $41.0 \pm 1.4$ & $13.6 \pm 0.5$ & $7.19 \pm 0.06$ & $59.0 \pm 1.2$ & $33.0 \pm 0.0$ \\
\hline $\mathrm{TPP}+\mathrm{HgCl}_{2}$ & $43.0 \pm 1.4$ & $14.7 \pm 0.6$ & $7.25 \pm 0.12$ & $60.0 \pm 2.65$ & $33.3 \pm 0.6$ \\
\hline
\end{tabular}

Table 3: Effect of TPP and $\mathrm{HgCl}_{2}$ on some Leukocyte indices of male Wistar rats.

\begin{tabular}{lcccc}
\hline Groups & $\begin{array}{c}\text { WBC } \\
(\mathbf{x 1 0} / \boldsymbol{\mu} \mathbf{L})\end{array}$ & $\begin{array}{c}\text { Lymphocytes } \\
(\mathbf{x 1 0} / \boldsymbol{\mu} \mathbf{L})\end{array}$ & $\begin{array}{c}\text { Neutrophils } \\
(\mathbf{x 1 0} / \boldsymbol{\mu} \mathbf{L})\end{array}$ & $\begin{array}{c}\text { Thrombocytes } \\
(\mathbf{x 1 0} / \boldsymbol{\mu} \mathbf{L})\end{array}$ \\
\hline Control & $5.58 \pm 1.51$ & $3.1 \pm 0.4$ & $4.0 \pm 1.3$ & $1005 \pm 354$ \\
$\mathrm{PG}$ & $5.80 \pm 1.71$ & $2.6 \pm 1.6$ & $2.2 \pm 0.8$ & $1037 \pm 418$ \\
$\mathrm{TPP}$ & $3.75 \pm 1.2$ & $2.5 \pm 0.6$ & $2.7 \pm 0.9$ & $620 \pm 240$ \\
$\mathrm{HgCl}_{2}$ & $4.43 \pm 1.81^{*}$ & $2.1 \pm 0.7 *$ & $2.0 \pm 1.2^{*}$ & $800 \pm 283^{*}$ \\
$\mathrm{TPP}+\mathrm{HgCl}_{2}$ & $4.98 \pm 1.9$ & $2.8 \pm 1.5$ & $3.3 \pm 1.2^{* *}$ & $930 \pm 409^{*}$ \\
\hline
\end{tabular}

Values are expressed as mean \pm S.D. of six animals. PG, propylene glycol; TPP, tomato pomace powder; $\mathrm{HgCl}_{2}$, mercuric chloride. $* \mathrm{P}<0.05$ versus Control group; $* *=\mathrm{P}<0.05$ versus $\mathrm{HgCl}_{2}$ group. 
A

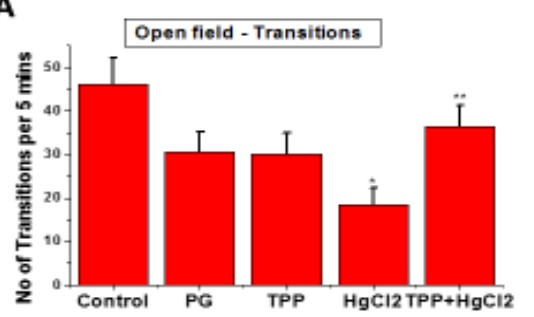

C

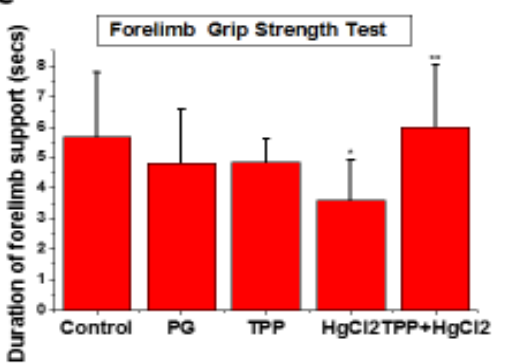

B

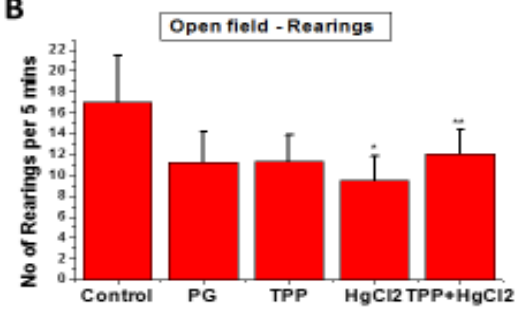

D

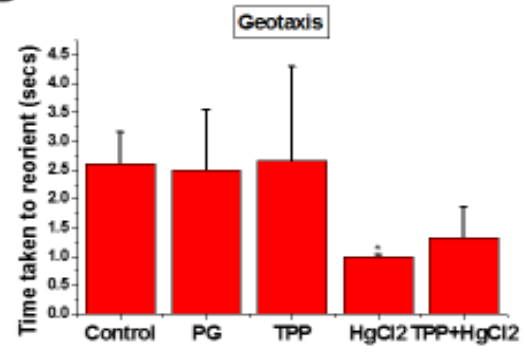

Figure 1: Histogram of behavioural tests in the control and treated groups. A: Horizontal movements measured as number of open field transitions, B: Vertical movements measured as number of open field rearings, C: forelimb muscular strength measured as the length of time rats remain suspended on the metal wire, D: negative geotaxis, measured as time taken for rats to re-orient in a head-up direction. Movements, forelimb strength and geotaxis were significantly reduced by $\mathrm{HgCl}_{2}$ treatment whereas pre-treatment with TPP ameliorated movements and forelimb strength significantly ( $<0.05$ ). PG, propylene glycol; TPP, tomato pomace powder; $\mathrm{HgCl}_{2}$, mercuric chloride. Values are expressed as mean \pm S.D. of six animals. ${ }^{*} \mathrm{P}<0.05$ versus Control group; $* *=\mathrm{P}<0.05$ versus $\mathrm{HgCl}_{2}$ group.
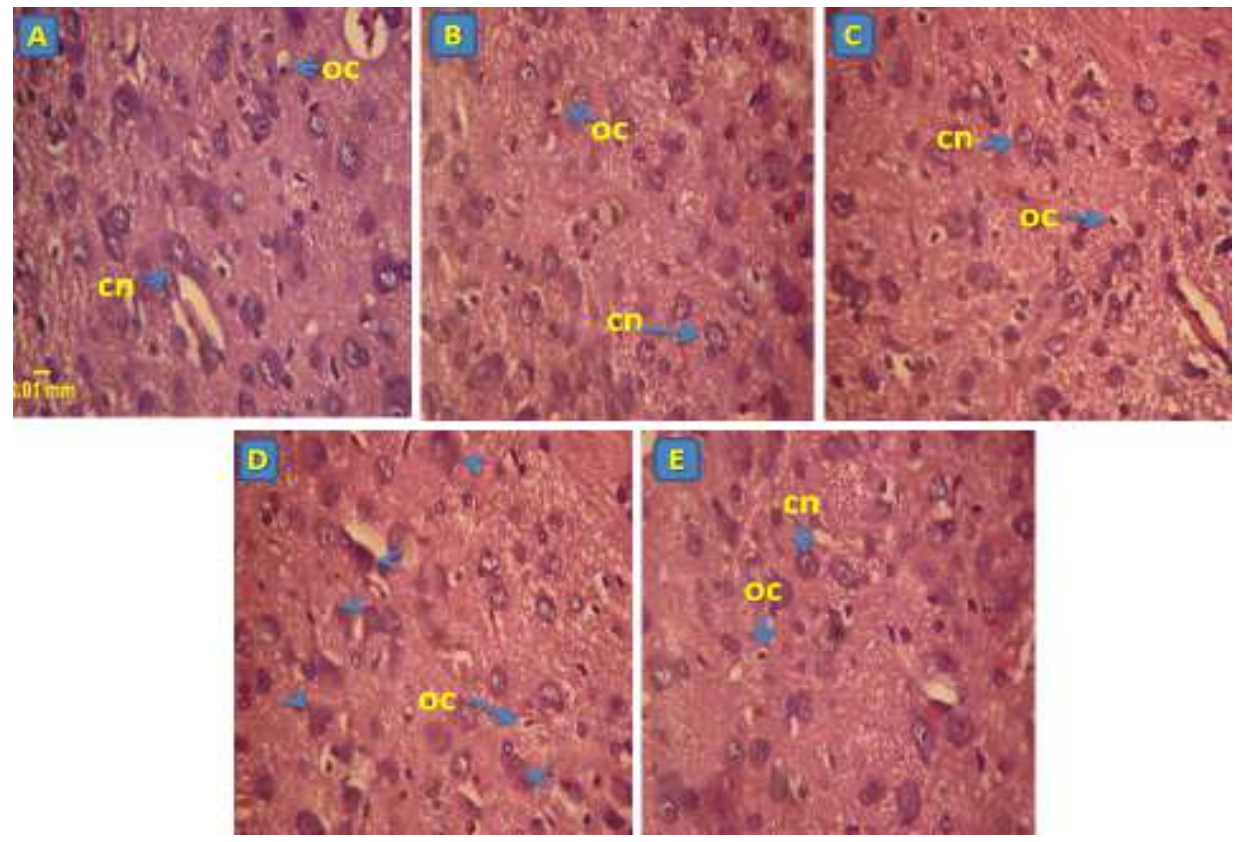

Figure 2: Representative stained sections of cerebral cortex of rats. (A) Control (B) PG-treated (C) TPPtreated (D) $\mathrm{HgCl}_{2}$-treated (E) TPP+ $\mathrm{HgCl}_{2}$-treated. Observe that neurons in $\mathrm{A}, \mathrm{B}$, and $\mathrm{C}$ are healthy. In group $\mathrm{D}$, mercury treatment induced neuronal degeneration (arrowheads). Pre-treatment with TPP partially ameliorated the neuronal degeneration as normal neurons predominated. PG, propylene glycol; TPP, tomato pomace powder; $\mathrm{HgCl}_{2}$, mercuric chloride; cn, cortical neuron; oc, oligodendrocytes. H\&E. Calibration bar for all figures $=0.01 \mathrm{~mm}(10 \mu \mathrm{m})$. 

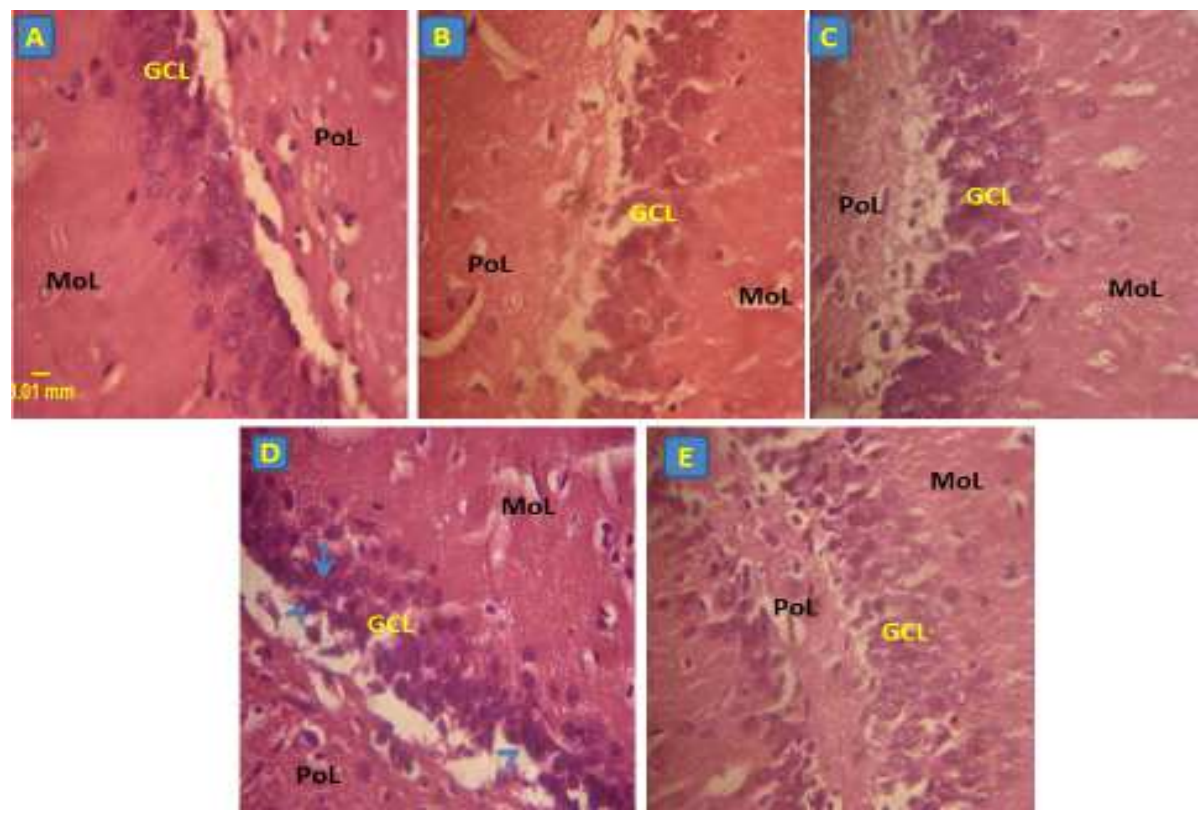

Figure 3:Representative stained sections of dentate gyrus of rats. (A) Control (B) PG-treated (C) TPPtreated (D) $\mathrm{HgCl}_{2}$-treated group shows scattered pyknotic neurons in GCL (arrowheads) at the subgranular zone, whereas the neurons are normal on the outer portion (arrows) (E) $\mathrm{TPP}+\mathrm{HgCl}_{2}$-treated rats show predominant normal granule neurons. PG, propylene glycol; TPP, tomato pomace powder; $\mathrm{HgCl}_{2}$, mercuric chloride; $\mathrm{MoL}$, molecular layer; $\mathrm{GCL}$, granular cell layer; PoL, polymorphic layer. H\&E. Calibration bar for all figures $=0.01 \mathrm{~mm}(10 \mu \mathrm{m})$.
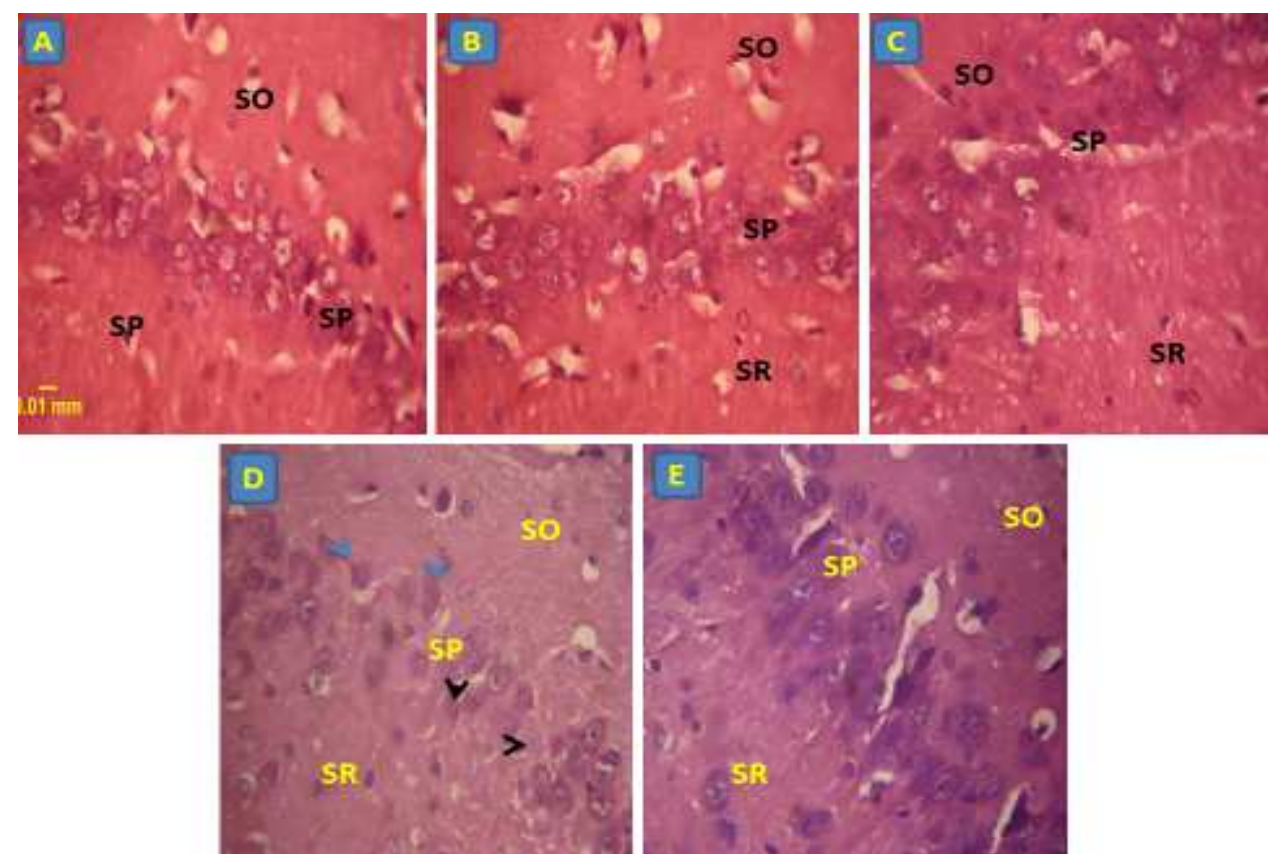

Figure 4: Representative stained sections of Cornu Ammonis3 of rats. (A) Control (B) PG-treated (C) TPP-treated (D) $\mathrm{HgCl}_{2}$-treated rats show degenerating pyramidal neurons (pyknotic neurons, blue arrowheads; karyolitic neurons, black arrowheads), (E) $\mathrm{TPP}+\mathrm{HgCl}_{2}$-treated rats show normal pyramidal neurons. $\mathrm{PG}$, propylene glycol; TPP, tomato pomace powder; $\mathrm{HgCl}_{2}$, mercuric chloride; SO, stratum oriens; SP, stratum pyramidalis; SR, stratum radiatum. H\&E. Calibration bar for all figures $=0.01 \mathrm{~mm}(10 \mu \mathrm{m})$. 


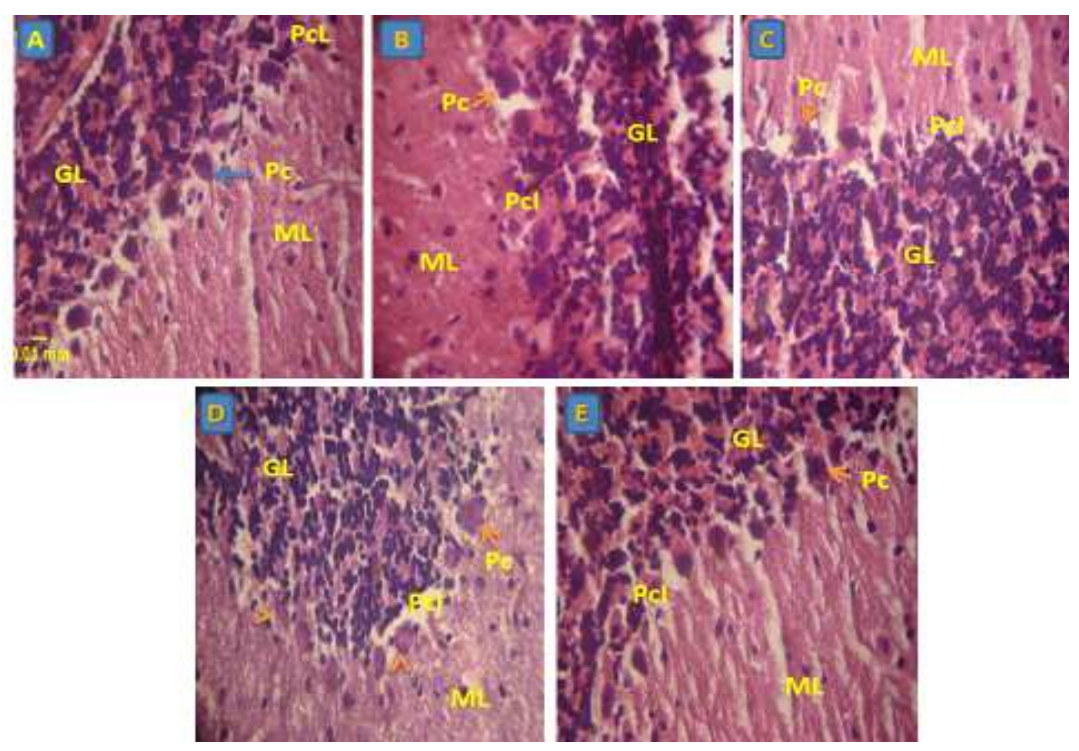

Figure 5: Representative stained sections of cerebellum of rats. (A) Control (B) PG-treated (C) TPP-treated (D) $\mathrm{HgCl}_{2}$-treated cerebellum with Purkinje neurons exhibiting eosinophilia and lacking the normal basophilic staining (arrowheads) (E) $\mathrm{TPP}+\mathrm{HgCl}_{2}$-treated. Purkinje cells exhibit normal basophilic staining nuclei in all other groups. PG, propylene glycol; TPP, tomato pomace powder; $\mathrm{HgCl}_{2}$, mercuric chloride $\left(\mathrm{HgCl}_{2}\right)$; $\mathrm{ML}$ - molecular layer; $\mathrm{GL}$ - granular layer; Pcl, Purkinje cell layer; Pc - Purkinje cells. H\&E. Calibration bar for all figures $=0.01 \mathrm{~mm}(10 \mu \mathrm{m})$.

\section{DISCUSSION}

In this present study, we presented data demonstrating the effectiveness of tomato pomace powder (TPP) in reversing some of the microanatomical, haematological and behavioural alterations induced by mercuric chloride $\left(\mathrm{HgCl}_{2}\right)$ treatment in male rats.

Our observation of death of cerebral cortical neurons as evidenced by presence of degenerated neurons is in agreement with reported findings (Eto et al., 2001; Ferraro et al., 2009) that the cerebral cortex is often affected by mercury intoxication. The vulnerability of the central nervous system (CNS) to mercury toxicity has been attributed to varying factors like oxidative stress due to free radical generation, neurotransmitter disruption, and stimulation of neural excitoxins, resulting in damage to many parts of the brain (Bernhoft, 2012). The ability of mercuric chloride to be converted to methyl mercury which can easily cross the bloodbrain barrier and accumulate in the brain at much higher concentrations encourages neurotoxicity (Clarkson and Magos, 2006).
This may explain the cellular death of cortical neurons in the MC treated group with implications of reduction or loss of frontal cortical functions like planning, movement coordination, social conduct and decision making (Tranel, 1995).

The finding of neuronal degeneration in the subgranular zone of the granule cell layer of the dentate gyrus (DG) of the rats is evidence of mercury injury and alteration from the normal cyto-architecture. This again suggested that mercuric chloride injured and elicited neuronal cell death in the hippocampal. The effect of $\mathrm{HgCl}_{2}$ on the pyramidal neurons of the cornu ammonis 3 (CA3) presents a severe alteration of the microanatomy of this portion of the brain. The toxicity of $\mathrm{HgCl}_{2}$ was demonstrated by cell death features ranging from pyknosis in the granule cells to karyolysis in the pyramidal neurons of the CA3 (Stevens and Lowe, 2000). This damage has demonstrated that the hippocampus is vulnerable to mercury toxicity and this effect may affect the dividing cells of the cells of the subgranular layer of the DG 
which contributes to adult neurogenesis. This severe cellular damage could affect the transmission of neural information from the perforant pathway to the DG and its projection to CA3 via the Mossy fibres (Scharfman, 2007). Memory and learning capacity of such animals might be affected which may lead to abnormal behaviour.

Our observation of the eosinophilic staining of the Purkinje cell nucleus in rats treated with $\mathrm{HgCl}_{2}$ indicated loss of nuclear material, unlike the deeply basophilic nucleus of the Purkinje cells in all the other groups. It was reported that mercury interferes with DNA transcription and protein synthesis (Bernhoft, 2012); damages DNA (Uma et al., 2012), and induces DNA single-strand breaks at low concentrations in mammalian cells (Fonfria et al., 2005). Our observation of Purkinje cell alteration may be explained by the fact that mercury attacks the nuclear DNA. Purkinje cells are the focal neurons of the cerebellar cortex since all afferent pathways ultimately converge on it and its axon constitute the major exit from the cerebellar cortex; hence death of the neurons will affect movement, posture and balance (Affi and Bergman, 2005). The significant reduction in movements, forelimb strength, geotaxis and rearing behavior which were induced by $\mathrm{HgCl}_{2}$ treatment suggested loss of motor and exploratory skills as well as loss of muscle strength which may be due the reduction in the functional efficiency of the cerebellum.

Our findings on the blood parameters of $\mathrm{HgCl}_{2}$ treated rats red blood cell is in disagreement with the report that $\mathrm{HgCl}_{2}$ depresses haeme synthesis, hence anticipating a reduction of the erythrocytic parameters (Bernhoft, 2012). There was a negligible alteration of red blood values which may be due to the short term administration that lasted only five days to the rats. The alteration in the profile of the leukocytes by $\mathrm{HgCl}_{2}$ may be due to the fact that erythrocytes have nuclei which $\mathrm{HgCl}_{2}$ might have attacked hence the reduction by mercury. Various workers, Hussain et al. (1997), Augusti et al. (2007), Rao and Purohit. (2011) and Uma et al.
(2012) have demonstrated that the reported mechanism of mercury intoxication via oxidative damage can be mitigated by antioxidants. Tomato has been reported to be rich in lycopene noted for its potent antioxidant effect on $\mathrm{HgCl}_{2}$ toxicity (Augusti et al., 2007). TPP has also been reported to provide antidotes to oxidative damage thus enhancing recovery from experimental cerebral ischaemia (Wattanathorn et al., 2012).

The neuronal cell death elicited by mercuric chloride in our results agreed with the reports of Ferraro et al. (2009) that mercury affects antioxidant mechanisms in the cell, resulting in cell degeneration, loss of membrane integrity and finally cellular necrosis. The presence of antioxidant activity in the TPP pre-treatment might have reduced this effect as shown by the absence of degenerating neurons and improvement of the haematological and behavioural parameters. TPP has demonstrated protective properties in this experiment, which we believe is due in part to its reported antioxidant property hence the mitigation of the alteration induced by $\mathrm{HgCl}_{2}$ in the various parameters studied. Since both acute and chronic exposure to mercury has been reported to cause a variety of neurological or psychiatric disorders $(\mathrm{Xu}$ et al., 2011), and our study has demonstrated the effects of the acute exposure, it will be expected that precautions against mercury food contamination, the main source being fish consumption, avoidance of contaminated drug and vaccine preservatives, careful use of dental amalgams, and protection from occupational exposure will be a worthwhile cause to be promoted.

\section{Conclusion}

Our data demonstrated that preexposure of rats to TPP for 14 days before treatment with $\mathrm{HgCl}_{2}$ reduced the alterations observed in the Purkinje cells, cortical neurons, dentate granule cells and hippocampal pyramidal neurons. Therefore tomato pomace may be considered a potential 
neuroprotective substance which needs further evaluation.

\section{ACKNOWLEDGEMENTS}

Authors gratefully acknowledge the review and valuable comments of Prof. V. O. Taiwo, Head, Department of Veterinary Pathology, University of Ibadan, Nigeria on the histology slides.

\section{REFERENCES}

Abramoff MD, Magalhaes PJ, Ram SJ. 2004. Image processing with ImageJ. Biophotonics International, 11(7): 36-42.

Afifi AK, Bergman RA. 2005. Functional Neuroanatomy: Text and Atlas ( $2^{\text {nd }}$ edn). McGraw-Hill: New York; 201-222.

Augusti PR, Conterato GMM, Somacal S, Einsfeld L, Ramos AT, Fernando Y. M. Hosomi FYM, Dominguita L, Graça DL, Tatiana ET. 2007. Effect of Lycopene on nephrotoxicity induced by mercuric chloride in rats. Bas Clin Pharm \&Tox., 100: 398-402.

Bancroft JD, Gamble M. 2008. Theory and Practice of Histology Techniques, (6th edn). Churchill Livingstone Elsevier: Philadelphia; 83 - 134.

Bernhoft RA. 2012. Mercury Toxicity and Treatment: A review of the literature. $J$ Environ and Pub Health, Article ID 460508, 10 pages doi:10.1155/2012/ 460508.

Clarkson TW, Magos L, Myers GJ. 2003. The toxicology of mercury - current exposures and clinical manifestation. N. Engl. J. Med, 49: 1731-1737.

Coccine Y, Randin G, Candura S, Nappi R, Procko PL, Luigi M. 2000. Low level of exposure of methyl mercury modifies muscarinic cholinergic receptor binding characteristic in rat brain and lymphocyte: Physiologic implication and new opportunities in biological monitoring. Environ. Health Perspec., 108: 29.

Eto K, Yasutake A, Kuwana T, Korogi Y, Akima M, Shimozeki T, Tokunaqa H, Kaneko Y. 2001. Methylmercury poisoning in common marmosets-a study of selective vulnerability within the cerebral cortex. Toxicol Pathol, 29(5): $565-573$.

Ezeuko VC, Nwokocha CR, Mounmbegna PE, Nriagu CC. 2007. Effects of Zingiber officinale on liver function of mercuric chloride-induced hepatotoxicity in adult Wistar rats. Rev Electron Biomed / Electron J. Biomed., 3: 40-45.

Farombi EO, Owoeye O. 2011. Antioxidative and Chemopreventive Properties of Vernonia amygdalina and Garcinia biflavonoid. Int. J. Environ. Res. Public Health, 8: 2533-2555.

Ferraro L, Tomasini MC, Tanganelli S, Mazza R, Coluccia A, Carratu MR, Gaetani S, Cuomo V, Antonelli T. 2009. Developmental exposure to Methylmercury elicits early cell death in the cerebral cortex and long-term memory deficits in the rat. Int. J. Dev. Neurosci., 27: 165-174.

Fonfria E, Vilaro MT, Babot Z, RodriguezFarre E, Sunol C. 2005. Mercury compounds disrupt neuronal glutamate transport in cultured mouse cerebellar granule cells. J. Neurosci. Res., 79: 545553.

Guzzi G, Pigatto PD, Spadari F, Laporta CAM. 2012. Effect of thimerosal, methylmercury, and mercuric chloride in Jurkat T Cell Line. Interdiscip Toxicol., 5(3): 159-161.

Hsiao G, Fong TH, Tzu NH, Lin KH, Chou DS, Sheu JR. 2004. A Potent Antioxidant, Lycopene, Affords Neuroprotection Against Microglia Activation and Focal Cerebral Ischemia in Rats. In vivo, 18: 351-356.

Hussain S, Rodgers DA, Duhart HM, Ali SF. 1997. Mercuric chloride-induced reactive oxygen species and its effect on antioxidant enzymes in different regions of rat brain. J. Environ. Sci. Health, 32(3):395-409.

Khalaf HHAM, Sharoba RA, El Sadani Fawzia M, El Nashabyand SM, Elshiemy. 2014. Antioxidant properties of some extracts from gamma irradiated tomato 
(Lycopersicon esculentum L.) pomace. J. Food and Dairy Sci., Mansoura Univ., 5(4): $247-263$.

Kreider JC, Blumberg MS. 1999. Geotaxis in 2-week-old Norway rats (Rattus norvegicus): A reevaluation. Dev. Psychobiol., 35(1): 35-42.

National Research Council (NRC). 2000. Toxicological Effects of Methylmercury. National Academy Press: Washington DC; 54-56.

Owoeye O, Adesida A, Onwuka SK, Farombi EO. 2010. Gamma radiation effects on the brain of rats: antioxidant and radioprotective properties of Vernonia amygdalina leaf extract. Int. J. Biol. Chem. Sci., 4(6): 2324-2336.

Olopade FE, Shokunbi MT, Sirén AL. 2012. The relationship between ventricular dilatation, neuropathological and neurobehavioural changes in hydrocephalic rats. Fluids and Barriers of the CNS, 9: 19. Downloaded on 12/12/2014 from: http://www. fluidsbarrierscns.com/content/9/1/19

Public Health Service (PHS). 1996. Public Health Service Policy on Humane Care and User of Laboratory Animals.US Department of Health and Human Services: Washington, DC; 99-158.

Rao MV, Purohit AR. 2011. Neuroprotection by Melatonin on mercury induced toxicity in the rat brain. Pharmacology \& Pharmacy, 2: 375-385.

Scharfman HE. 2007. The CA3 "backprojection" to the dentate gyrus. Prog. Brain Res., 163: 627-637.

Sheikh TJ, Patel BJ, Joshi DV, Patel RB, Jegoda MD. 2013. Repeated dose oral toxicity of inorganic mercury in Wistar rats: biochemical and morphological alterations, Vet World, 6(8): 563-567.
Snell RS. 2006. Clinical Neuroanatomy. $\left(6^{\text {th }}\right.$ edn). Lippincott Williams \& Wilkins Co.: Philadelphia; 298-308.

Stevens A, Lowe J. 2000. Pathology. (2th edn). Mosby: Edinburgh; 18-33.

Stohs SJ, Bagchi D. 1995. Oxidative mechanisms in the toxicity of metalsions. Free Radic. Biol. Med., 18: 321326.

Tamashiro KLK, Wakayama T, Blanchard RJ, Blanchard C, Yanagimachi R. 2000. Postnatal growth and behavioral development of mice cloned from adult cumulus cells. BiolReprod., 63: 328-334.

Tranel D. 1995. Higher brain functions. In Neuroscience in Medicine. Conn PM (ed). JB Lippincott Company: Philadelphia; 555-582

Uma C, Poornima K, Surya S, Ravikumar G, Gopalakrishnan 2012. Nephroprotective effect of ethanolic extract of Tabernaemontana coronaria in mercuric chloride induced renal damage in Wistar albino rats. J Environ Pub Health, 2012. Article ID 460508, 10 pages. doi:10.1155/2012/460508

Wattanathorn J, Thukham-Mee W, Muchimapura S, Tong-un T, Wannanon P. 2012. Tomato, a potential yin food, protects against stroke. Chinese Medicine, 3: 144-150.

Xu F, Farkas S, Kortbeek S, Zhang FX, Chen L, Zamponi GW, Syed NI. 2012. Mercury-induced toxicity of rat cortical neurons is mediated through N-methyl-DAspartate receptors. Mol. Brain, 5: 30. Downloaded on 12/12/2014 from: http://www.molecularbrain.com/content/5 $/ 1 / 30$. 